\title{
Internal pressure carrying capacity for different loading modes of filament-wound pipes from glass fiber-reinforced epoxy composites
}

\begin{abstract}
Development of a low-cost filament-winding machine is initially described in this paper. The filament-winding machine was used to fabricate composite pipes and the materials used were woven glass fiber and epoxy resin. The pipes were tested under three loading modes, namely mode I (hoop pressure loading), mode II (biaxial pressure loading), and mode III (biaxial pressure with axial compressive loading). The results reveal that filament-wound composite pipes should be wound at $75^{\circ}$ for hoop pressure loading (mode I), $55^{\circ}$ for biaxial pressure loading (mode II), and $85^{\circ}$ for biaxial pressure with axial compressive loading (mode III).
\end{abstract}

Keyword: Composite pipe; Filament winding; Internal pressure; Pressure carrying capacity 